\title{
Use of elastin fibre detection in the diagnosis of ventilator associated pneumonia
}

\author{
M El-Ebiary, A Torres, J González, A Martos, J Puig de la Bellacasa, M Ferrer, \\ R Rodriguez-Roisin
}

\begin{abstract}
Background - Elastin fibre detection could be a simple and reliable marker of ventilator associated pneumonia. To confirm this, a prospective study was undertaken to evaluate the diagnostic yield of elastin fibre detection in the diagnosis of ventilator associated pneumonia.
\end{abstract}

Methods - Seventy eight mechanically ventilated patients were evaluated by examining endotracheal aspirates for the presence of elastin fibres. All patients were previously treated with antibiotics. Quantitative bacterial cultures of endotracheal aspirates and protected specimen brush samples were also performed. Patients were classified into three diagnostic categories: group 1, definite pneumonia $(n=$ 25); group 2 , probable pneumonia ( $\mathbf{n}=$ $35)$; and group 3 , controls $(n=18)$.

Results - Patients with definite and probable pneumonia were grouped together. The presence of elastin fibres in endotracheal aspirate samples was more frequent in groups 1 and 2, being found in 19 of the 60 patients compared with five of the control group. Although the presence of elastin fibres had a low sensitivity (32\%), it was a reasonably specific marker $(72 \%)$ of pneumonia. This specificity increased to $86 \%$ and $81 \%$ respectively when only Gram negative bacilli and Pseudomonas aeruginosa pneumonia were considered. Again, calculated sensitivity was $43 \%$ and $44 \%$ when analysing cases infected by Gram negative bacilli and $P$ s aeruginosa, respectively. The negative predictive value of the detection of elastin fibres in pneumonia caused by Ps aeruginosa was $81 \%$. Detection was more frequent with infection by Gram negative bacilli (14/19), particularly with Ps aeruginosa (8/14). By contrast, pneumonia due to Gram positive cocci or non-bacterial agents uncommonly resulted in positive elastin fibre preparations $(4 / 19,21 \%)$. When analysing patients with and without chronic obstructive pulmonary disease, the diagnostic value of elastin fibre detection did not change.

Conclusions - Potassium hydroxide preparation of elastin fibres is a rapid and simple specific marker of ventilator associated pneumonia and may be a useful technique to help diagnose pulmonary infections in mechanically ventilated patients, although this assessment is at present limited to patients without adult respiratory distress syndrome.

(Thorax 1995;50:14-17)

Keywords: elastin fibres, quantitative cultures, endotracheal aspirates, nosocomial pneumonia.

Nosocomial pneumonia develops in $0.5-5 \%$ of all hospital admissions and is the second most frequent nosocomial infection. ${ }^{12}$ Patients receiving mechanical ventilation have a 4-21 times higher risk of developing nosocomial pneumonia, ${ }^{3}$ which accounts for one third of the overall mortality of patients who develop the condition. ${ }^{4}$ However, the fastest method of establishing a cause is still a matter of controversy. Clinical parameters, for instance, possess both low sensitivity and specificity. ${ }^{5-7}$ Several diagnostic techniques, such as quantitative cultures of bronchoalveolar lavage fluid or protected specimen brush samples, are excellent methods for establishing the diagnosis, but are associated with complications and with false negative or false positive results. ${ }^{89}$ Endotracheal aspirate samples have recently been used with quantitative cultures as sensitive and specific as non-invasive techniques for the diagnosis of ventilator associated pneumonia. ${ }^{1011}$ The use of specific markers of nosocomial pneumonia - namely, the presence of intracellular microorganisms, ${ }^{12}$ the levels of endotoxins in the bronchoalveolar lavage fluid,,$^{13}$ and the detection of elastin fibres ${ }^{14}$ - may be of importance as they can provide a rapid diagnosis of nosocomial pneumonia. The latter technique, originally described for the diagnosis of pulmonary tuberculosis, ${ }^{15}$ is a simple microscopic method of visualising elastin fibres in bronchial secretions. Studies from one group have reported reasonable diagnostic value for this method in mechanically ventilated patients with nosocomial pneumonia. ${ }^{1416}{ }^{17}$ The purpose of the current study was to evaluate endotracheal aspirate samples as biological markers of nosocomial pneumonia in patients receiving mechanical ventilation.

\section{Methods}

PATIENTS

Seventy eight mechanically ventilated patients were studied prospectively by two of the authors (ME and AT). Patients (cases and controls) were only included in the study if they remained intubated and mechanically ventilated for more than 72 hours. Immunosuppressed patients 
and adult patients with acute respiratory distress syndrome were excluded. Informed consent was obtained in each case.

Patients were classified into one of the following categories: group 1, patients with definite pneumonia $(n=25)$ having one of the following: (a) positive pleural fluid or blood cultures for the same organism isolated from respiratory secretions, (b) histopathological or necropsy findings compatible with pneumonia, and (c) isolation of definite respiratory pathogens, such as Legionella; group 2, patients with probable pneumonia $(n=35)$ who had new or progressive pulmonary infiltrates in addition to one of the following: (a) purulent respiratory secretions, (b) pyrexia $\geqslant 38 \cdot 3^{\circ} \mathrm{C}$, and (c) $\geqslant 25 \%$ increase in circulating leucocytes; group 3, patients who had neither chest radiographic findings, leucocytosis, nor fever (control group, $n=18$ ). The underlying conditions of the patients in the three groups are summarised in table 1.

Sterile endotracheal aspirates were obtained using a 22-inch, 14-Fr suction catheter and collected in a mucus collector (Mocstrap; Proclinics, Barcelona, Spain). Fibreoptic bronchoscopy (BFT 3R; Olympus, New York, USA) was performed one hour later to obtain a protected specimen brush sample (BFW 1.0/ 70/90; Medi-Tech Inc, Water-Town, Massachusetts, USA). All samples were retrieved at the time the clinical diagnosis of pneumonia was made in groups 1 and 2 .

\section{MICROBIOLOGICAL METHODS}

Endotracheal aspirates and protected specimen brush samples were delivered to the microbiology laboratory within 15 minutes of collection. A purulent portion was mixed in a $1: 1$ (volume:volume) ratio with $40 \%$ potassium hydroxide, vortexed with glass beads, and incubated at $37^{\circ} \mathrm{C}$ for 30 minutes. A drop was placed on a clean glass slide and a cover slip dropped over the sample. Elastin fibres were examined by light microscopy at $100 \times$ magnification and were also observed at $400 \times$ to confirm the presence of the characteristic clumps with their split end. ${ }^{1617}$

Quantitative cultures of endotracheal aspirate and protected specimen brush samples were performed according to previously described methods. ${ }^{811}$ Serial dilutions of endotracheal aspirate and protected specimen brush samples were prepared. One hundred $\mu$ l of each

Table 1 Underlying conditions of patients in the three diagnostic categories

\begin{tabular}{llll}
\hline & $\begin{array}{l}\text { Group 1 } \\
\text { (definite pneumonia) } \\
(n=25)\end{array}$ & $\begin{array}{l}\text { Group 2 } \\
\text { (probable pneumonia) } \\
(n=35)\end{array}$ & $\begin{array}{l}\text { Group 3 } \\
\text { (control) } \\
(n=18)\end{array}$ \\
\hline COPD & $15(60 \%)$ & $18(51 \%)$ & $8(44 \%)$ \\
Postoperative & $2(8 \%)$ & $5(14 \%)$ & $3(17 \%)$ \\
Cranial trauma & $3(12 \%)$ & $6(17 \%)$ & $6(33 \%)$ \\
Heart failure & $1(4 \%)$ & $1(3 \%)$ & - \\
CVA & $1(4 \%)$ & $2(6 \%)$ & - \\
Sarcoidosis & $1(4 \%)$ & $-1(3 \%)$ & - \\
Hypertension & - & $1(3 \%)$ & - \\
Diabetes mellitus & $2(8 \%)$ & $1(3 \%)$ & - \\
Unknown & $2(5 \%)$ & \\
\hline
\end{tabular}

$\mathrm{COPD}=$ chronic obstructive pulmonary disease $\mathrm{CVA}=$ cerebrovascular accident. dilution was cultured on different media. All cultures were incubated at $37^{\circ} \mathrm{C}$ under aerobic and anaerobic conditions in a $\mathrm{CO}_{2}$ enriched atmosphere. Cultures were evaluated for growth 24 and 48 hours later and were discarded if negative after five days, except for fungal media which were discarded after 30 days. Serological tests for Legionella pneumophila, Mycoplasma pneumoniae, Coxiella burnetii, and Chlamydia psittaci were performed on all patients at the time of entry into the study and repeated two weeks later to detect rising titres.

\section{STATISTICAL ANALYSIS}

The unmatched sample size to allow the detection of elastin fibre in an expected $35 \%$ of cases compared with an expected $0.01 \%$ in the controls with an $\alpha$ error $<0.05$ and a power $(1-\beta)$ of $80 \%$ was calculated. By trial and error it was established that an odds ratio of 5 would require at least 54 cases (groups 1 and 2) and 18 controls. $^{18}$

For the comparison of means the non-parametric Mann-Whitney test was used for quantitative variables and the $\chi^{2}$ test (Fisher's exact test when needed) to compare proportions. The Mantel-Haenzel test, the levels of significance, the odds ratios, and their confidence intervals were calculated using EPIinfo software. ${ }^{19}$ All reported $p$ values are two-tailed. Diagnostic values of different tests were calculated according to standard formulae and compared by different thresholds of $\mathrm{McNe}$ mar's test. ${ }^{20}$

\section{Results}

STUDY POPULATION

The 78 patients comprised 70 men and eight women with a mean (SD) age of 58 (15) years. All patients were mechanically ventilated for a mean of $9 \cdot 2(4 \cdot 2)$ days and all had commenced antibiotics (4 (2) days) before their entry into the study. The administered antibiotics included third generation cephalosporins in 43 cases, aminoglycosides in 30 , macrolides in 10 , ciprofloxacin in six, imipenem in 10, vancomycin in four, rifampicin in one, clindamycin in two, sulphamethoxazole trimethoprim in two, metronidazole in two, second generation cephalosporins in one, and isoniazid in one. Four patients received $\beta$-lactams other than cephalosporins. Twenty five received monotherapy.

The demographic and clinical features of the patients are summarised in table 2. No significant differences were seen. The most common underlying condition in all groups was chronic obstructive pulmonary disease (COPD) (41 cases). There were no patients with a clinical history of bronchiectasis.

\section{MICROBIOLOGICAL EXAMINATION}

A mean of $2.4(1.5) \mathrm{ml}$ of purulent secretions was obtained from all patients at each aspiration. Seven of 25 samples (28\%) were positive for elastin fibres in group 1 (definite 
Table 2 Mean (SD) data of the patients studied

\begin{tabular}{llll}
\hline & $\begin{array}{l}\text { Group 1 } \\
\text { (definite pneumonia) } \\
(n=25)\end{array}$ & $\begin{array}{l}\text { Group 2 } \\
\text { (probable pneumonia) } \\
(n=35)\end{array}$ & $\begin{array}{l}\text { Group 3 } \\
\text { (control) } \\
(n=18)\end{array}$ \\
Age (years) & $60(13 \cdot 4)$ & $56 \cdot 6(18)$ & $58(14)$ \\
$\mathrm{MV}$ period (days) & $5 \cdot 8(3 \cdot 4)$ & $7 \cdot 1(7 \cdot 15)$ & $11(2)$ \\
Leucocytes $\left(\times 10^{9} / \mathrm{ml}\right)$ & $14 \cdot 5(5 \cdot 2)$ & $13 \cdot 9(7 \cdot 2)$ & $9 \cdot 5(2 \cdot 3)$ \\
Temperature $\left({ }^{\circ} \mathrm{C}\right)$ & $37 \cdot 9(0 \cdot 7)$ & $37 \cdot 5(0 \cdot 7)$ & $36 \cdot 9(0 \cdot 9)$ \\
SAPS & $10 \cdot 5(3 \cdot 4)$ & $9 \cdot 2(2 \cdot 9)$ & $9 \cdot 6(3 \cdot 9)$ \\
$\mathrm{PaO}_{2} / \mathrm{FIO}_{2}(\mathrm{kPa})$ & $28(13)$ & $31(10)$ & $34(9 \cdot 9)$ \\
\hline
\end{tabular}

MV = mechanical ventilation period (days) before the study; SAPS = simplified acute physiological score.
lo revealed the presence of Staphylococcus aureus in two cases. The remaining three cases had negative cultures.

\section{Discussion}

The most important finding of the present study is that the detection of elastin fibres in endotracheal aspirates of mechanically ventilated patients previously treated with antibiotics is associated with a reasonably specific biological marker of ventilator associated pneumonia. In pneumonia caused by Gram negative bacilli, particularly Ps aeruginosa, this technique had a reasonable sensitivity. Nevertheless these findings are at present limited to adult patients without adult respiratory distress syndrome.

The diagnosis of ventilator associated pneumonia is difficult for several reasons. Firstly, clinical parameters show a large percentage of false positive and false negative results. ${ }^{5-7}$ Secondly, microbiological diagnosis based on quantitative cultures of protected specimen brush, bronchoalveolar lavage, or endotracheal aspirate samples also present false positive and false negative results. ${ }^{21-23}$ Furthermore, definite results are delayed for 48-72 hours. For all these reasons it would be an advantage to have a biological marker of ventilator associated pneumonia as a rapid alternative diagnostic method in clinical practice. Intracellular microorganisms in bronchoalveolar lavage fluid, levels of endotoxin, and elastin fibre detection are the three currently used methods. ${ }^{12-14}$ The first two require bronchial lavage, not always available in an intensive care setting, and, furthermore, the second method is still viewed as a research tool. By contrast, elastin fibre detection seems to be a simple, rapid and cheap technique that can be processed from samples that are easy to obtain such as endotracheal aspirates.

In 1846 der Kolk described a simple bedside test for the diagnosis of necrotising pneumonia. ${ }^{15}$ Since then, and with a few exceptions, ${ }^{14161724}$ this test has been neglected. Shlaes et $a l^{1617}$ studied the usefulness of the method in detecting necrotising pneumonia in nonventilated patients and showed it to be more sensitive than chest radiography. Interestingly, many of the pneumonias with positive elastin fibre preparations in the present study were caused by $P s$ aeruginosa, suggesting that this technique is more sensitive in Gram negative bacillary pneumonia. This could be explained by the necrotising potential of these microorganisms compared with most Gram positive cocci. However, these results may be biased by the high prevalence of Ps aeruginosa pneumonia found in our series. More studies are needed to compare the diagnostic value of elastin fibre detection in Gram negative bacilli and Gram positive cocci pneumonias.

We found a low sensitivity (32\%) but reasonable specificity $(72 \%)$ of the elastin fibre technique for detecting ventilator associated pneumonia. Sensitivity increased to $43 \%$ and $44 \%$ for Gram negative bacilli or Ps aeruginosa alone. However, the negative predictive value of detection of elastin fibres in pneumonias 
caused by Ps aeruginosa is $81 \%$ which means that, in the absence of a positive elastin fibre preparation, the probability of isolating Ps aeruginosa is low (19\%). Salata et al $^{14}$ prospectively studied 51 intubated patients by serial examination of their tracheal aspirates for graded Gram stains, quantitative cultures, and elastin fibres. The presence of elastin fibres in the tracheal aspirates, identified after the addition of $40 \%$ potassium hydroxide, was highly specific for a necrotising pneumonia (Gram negative bacilli and Staphylococcus aureus). This technique, although not very sensitive ( $52 \%)$, had a specificity and a positive predictive value of $100 \%$ for infection. It also preceded the radiographic evidence of pulmonary infiltrates by $1.8(1 \cdot 3)$ days.

Several considerations in our study deserve particular attention. Firstly, the whole population had already been treated with antibiotics and we have not considered how antibiotics could modify the sensitivity of this technique. Other studies do not specifically mention this point. ${ }^{14}$ Secondly, specificity was studied in only the control patients which is a substantial limitation. Other reports on patients with acute respiratory distress, in whom histological necrosis without infection can exist, detected a positive predictive value of $50 \%$ for ventilator associated pneumonia. ${ }^{24}$ Thirdly, more than $50 \%$ of our patients had COPD which did not influence elastin fibre detection. Finally, the evaluation of elastin fibres was performed only once, at the time of diagnosis of pneumonia, and not sequentially, which limits the diagnostic value, prediction, and prognosis of our results. Importantly, the value of a sequential study relies on knowing if an appropriate antibiotic treatment may alter elastin fibre detection and how rapidly that can occur. Also, the relationship between mortality and the accurate diagnosis of ventilator associated pneumonia with a marker such as elastin fibre detection is unknown. ${ }^{25}$ Soto et $a l,{ }^{26}$ using Verhoeff's stain, found a relationship between mortality and recurrence of elastin fibre detection when measured serially in a group of patients with ventilator associated pneumonia. Since we did not include immunosuppressed patients and those with adult respiratory distress syndrome in the current study, our results, particularly with regard to specificity, could be less significant when studying this population.

In conclusion, elastin fibre detection is a cheap, rapid and reasonably specific method for diagnosing ventilator associated pneumonia, which should be considered when analysing respiratory samples in mechanically ventilated patients. The presence of elastin fibres may help to decide on the initial antibiotic strategy for ventilator associated pneumonia.

\footnotetext{
1 Craven DE, Barber TW, Steeger KA, Montecalvo MA. Nosocomial pneumonia in the 1990s: update of epidemiology and risk factors. Semin Respir Infect 1990;5: demiology
}

2 Haley RW, Curver DH, White JW. The nation wide nosocomial infection rate. A new need for vital statistics. $\mathrm{Am}$ 7 Epidemiol 1985;121:159-67.

3 Celis R. Torres A, Gatell JM, Almela M, Rodriguez-Roisin R, Augustí Vidal A. Nosocomial pneumonia: a multivariate analysis of risk and prognosis. Chest 1988;93:318-24.

4 Craven DE, Kunches LM, Kilinsky V, Lichtenberg DA, Make BJ, McCabe WR. Risk factors for pneumonia and fatality in patients receiving continuous mechanical ventilation. Am Rev Respir Dis 1986;133:792-6.

5 Andrews CP, Coalson JJ, Smith JD, Johanson WG. Diagnosis of nosocomial bacterial pneumonia in acute diffuse lung injury. Chest 1981;80:254-8.

6 Bell RC, Coalson JJ, Smith JD, Johanson WG. Multiple organ system failure and infection in adult respiratory distress syndrome. Ann Intern Med 1983;99:293-8.

7 Fagon JY, Chastre J, Hance AJ, Guiguet M, Trouillet JM, Domart $\mathrm{Y}$, et al. Detection of nosocomial lung infection in ventilated patients: use of a protected specimen brush and quantitative culture technique in 147 patients. $\mathrm{Am}$ Rev Respir Dis 1988;138:110-6.

8 Wimberley N, Faling LJ, Bartlett JG. A fiberoptic bronchoscopy technique to obtain uncontaminated lower airway secretions for bacterial culture. Am Rev Respir Dis 1979;119:337-43.

9 Torres A, De La Bellacasa JP, Xaubet A, Gonzalez J, Rodriguez-Roisin R, Jimenez De Anta MT, et al. Diagnostic value of quantitative cultures of bronchoalveolar lavage and telescoping plugged catheter in mechanically ventilated patients with bacterial pneumonia. Am Rev Respir Dis 1989;140:306-10.

10 Marquette CH, Georges H, Wallet F, Ramon P, Saulnier F, Neviere R, et al. Diagnostic efficiency of EA with quantitative bacterial cultures in intubated patients with suspected pneumonia. Comparison with protected specimen brush. Am Rev Respir Dis 1993;148:138-44.

11 El-Ebiary M, Torres A, Gonzalez J, Puig de la Bellacasa J, García C, Jimenez de Anta MT, et al. Quantitative cultures of endotracheal aspirates for the diagnosis of ventilatorassociated pneumonia. Am Rev Respir Dis 1993;148: 1527.

12 Chastre J, Fagon JY, Soler P, Domart Y, Pierre J, Dombret MC. Quantification of BAL cells containing intracellular bacteria rapidly identifies ventilated patients with nosocomial pneumonia. Chest 1989;95:190-2S.

13 Pugin J, Auchenthaler R, Delaspre O, Van Gessel E, Suter PM. Rapid diagnosis of Gram negative pneumonia by assay of endotoxin in BAL fluid. Thorax 1992;47:547-9.

14 Salata R, Lederman MM, Shlaes DM, Jacobs MR, Eckstein $\mathrm{E}$, Tweardy D, et al. Diagnosis of nosocomial pneumonia in intubated, intensive care unit patients. Am Rev Respir Dis $1987 ; 135: 426-32$

15 Schroeder van der Kolk JLC. The presence of elastin fibers in the sputum of phthistics as a sure sign of a necrotic in the sputum of phthistics as a sure

16 Shlaes DM, Lederman MM, Chmielewski R, Tweardy D, Wolinsky E. Elastin fibers in the sputum of patients with necrotizing pneumonia. Chest 1983;83:885-9.

17 Shlaes DM, Lederman MM, Chmielewski R, Tweardy D, Krause G, Safai C. Sputum elastin fibers and the diagnosis of necrotizing pneumonia. Chest 1984;85:763-6.

18 Pocock SJ. Clinical trials: a practical approach. Chichester, UK: John Wiley, 1983;231-3.

19 Dean AG, Dean JA, Burton AH, Dicker RC. EPIinfo, Version 5.01: a word processing, database, and statistics program for epidemiology on microcomputers. Epidemiology Program Office, Atlanta: Centers for Disease Control, 1990.

20 Griner PF, Mayewski RJ, Mushlin AI, Grunland P. Selection and interpretation of diagnostic tests and procedures. Ann Intern Med 1981;94:533-600.

21 Torres A, Martos A, Puig de la Bellacasa J, Ferrer M, ElEbiary M, González J, et al. Specificity of endotracheal aspiration, protected specimen brush, and bronchoalveolar lavage in mechanically ventilated patients. Am Rev Respir lavage in mechanically

22 Rouby JJ, Martin De Lassale EM, Poete P, Nicolas MH, Bodin L, Jarlier V, et al. Nosocomial bronchopneumonia in the critically ill. Am Rev Respir Dis 1992;146:1059-66.

23 Torres A, El-Ebiary M, Padró L, González J, Puig de la Bellacasa J, Ramirez J, et al. Validation of different techniques for the diagnosis of ventilator-associated pneumonia Comparison with immediate postmornpulmonary biopsy. Am 7 Respir Crit Care Med 1994;149: pulmonary

24 Meduri GU. Ventilator-associated pneumonia in patients with respiratory failure. A diagnostic approach. Chest 1990; 97:1208-19.

25 Niederman MS, Torres A, Summer W. Invasive diagnostic testing is not needed routinely to manage ventilator-associated pneumonia. Am 7 Respir Crit Care Med 1994;150: 565-9.

26 Soto L, Soler T, Gajardo G, Zagolin B. Fibras de elastina en la secreción traqueobranquial y su correlación con la neumonía nosocomial en la UCI. Medicina Intensiva 1992; 16:535-41. 